\title{
Progress of Research and Development of Fundamental Technologies for Accelerator Magnets Using Coated Conductors
}

\section{AUTHOR(S):}

Amemiya, Naoyuki; Goda, Kazuhiro; Otake, Hiroaki; Nakamura, Taketsune; Ogitsu, Toru; Koyanagi, Kei; Kurusu, Tsutomu; ... Iwata, Yoshiyuki; Noda, Koji; Yoshimoto, Masahiro

\section{CITATION:}

Amemiya, Naoyuki ... [et al]. Progress of Research and Development of Fundamental Technologies for Accelerator Magnets Using Coated Conductors. IEEE Transactions on Applied Superconductivity 2013, 23(3): 4601905.

\section{ISSUE DATE:}

2013-02

URL:

http://hdl.handle.net/2433/173724

\section{RIGHT:}

(c) 2013 IEEE. Personal use of this material is permitted. Permission from IEEE must be obtained for all other uses, in any current or future media, including reprinting/republishing this material for advertising or promotional purposes, creating new collective works, for resale or redistribution to servers or lists, or reuse of any copyrighted component of this work in other works.; この論文は出版社版でありません。引用の際には出版社版をご確認ご利用ください。;This is not the published version. Please cite only the published version. 


\title{
Progress of Research and Development of Fundamental Technologies for Accelerator Magnets Using Coated Conductors
}

\author{
Naoyuki Amemiya, Kazuhiro Goda, Hiroaki Otake, Taketsune Nakamura, Toru Ogitsu, Kei Koyanagi, \\ Tsutomu Kurusu, Yoshiharu Mori, Yoshiyuki Iwata, Koji Noda, and Masahiro Yoshimoto
}

\begin{abstract}
A project to develop the fundamental technologies for accelerator magnets using coated conductors is in progress. A coil-dominated magnet and an iron-dominated magnet were designed, based on the conceptual design of spiral sector FFAG (Fixed Field Alternating Gradient) accelerator for carbon cancer therapy and that for accelerator-driven subcritical reactor, respectively. The required winding technologies were clarified through designing the magnets, and the R\&D of winding technologies for coils with three-dimensional shape and those with negative bend have been carried out. The influence of the magnetization of coated conductors on the field quality of magnets was studied experimentally.
\end{abstract}

Index Terms-accelerator magnets, coated conductors, FFAG accelerators, high temperature superconductors, magnetization.

\section{INTRODUCTION}

$\mathrm{T}$ HE APPLICATIONS of high $T_{\mathrm{c}}$ superconductors (HTS) to accelerator magnets have been studied to increase magnetic fields or to reduce electricity consumption [1]-[20]. We have been carrying out a project to develop fundamental technologies for HTS accelerator magnets since 2010 [8]-[14]. Our target applications are carbon cancer therapy and accelerator-driven subcritical reactor (ADSR). Downsizing an accelerator by increasing the magnetic fields is attractive for the former, and reducing electricity consumption is attractive for the later. Among various HTSs, we focus on coated conductors, because of their large critical currents in high magnetic fields and their high mechanical strengths. The Stage I of the project, whose targets are the conceptual designs of accelerators using HTS magnets as well as those of the

Manuscript received October 9, 2012. This work was supported by Japan Science and Technology Agency under Strategic Promotion of Innovative Research and Development Program.

N. Amemiya, K. Goda, H. Otake, and T. Nakamura are with Department of Electrical Engineering, Kyoto University, Kyoto 615-8510, Japan (phone: 8175-383-2220; fax: 81-75-383-2224; e-mail: amemiya.naoyuki.6a@kyotou.ac.jp.).

T. Ogitsu is with High Energy Accelerator Research Organization, Tokai 319-1195, Japan (email: ogitsu@post.kek.jp).

K. Koyanagi and T. Kurusu are with Toshiba Corporation, Tokyo 1058001, Japan (email: tsutomu.kurusu@toshiba.co.jp).

Y. Mori is with Research Reactor Institute, Kyoto University, Kumatori 590-0494, Japan (email: mori@rri.kyoto-u.ac.jp).

Y. Iwata and K. Noda are with National Institute of Radiological Sciences, Chiba 263-8555, Japan (email: noda_k@nirs.go.jp).

M. Yoshimoto is with Japan Atomic Energy Agency, Tokai 319-1195, Japan (email: yoshimoto.masahiro@jaea.go.jp). magnets themselves, was finished successfully. We also started the R\&D of the fundamental technologies. In the fouryear Stage II, which started in April 2012, we will establish the fundamental technologies and will integrate them into a model magnet for their demonstration.

In this paper, we report the progress of the project on the following topics: the magnet designs which are compatible with the designs of FFAG (Fixed-Field Alternating Gradient) accelerator [20]-[22]; winding technologies enabling designed magnets; the influence of the magnetization of coated conductors on the field quality, which is a critical issue to apply HTSs with tape shape to accelerator magnets.

\section{DESIGNS OF ACCELERATORS}

Three designs of accelerators are listed in Table I. The footprints of magnets are shown in Fig. 1 for the accelerators $\mathrm{R}-\mathrm{C}$ and S-C. Defocusing magnets, which are required in radial sector FFAG accelerators for alternating gradient but bend particle beams outward, can be eliminated in spiral sector FFAG accelerators. In spiral sector FFAG accelerators, the alternating gradient is realized by the nonlinear radial magnetic field profile and the spiral shape of magnets. The elimination of defocusing magnets reduces the diameter of an accelerator as well as the entire length of required conductors.

TABLE I

OUTLINE OF ACCELERATOR DESIGNS

\begin{tabular}{cccc}
\hline \hline Name & R-C & S-C & S-A \\
\hline Type & $\begin{array}{c}\text { Radial sector } \\
\text { (FDF triplet) } \\
\text { Carbon cancer } \\
\text { therapy }\end{array}$ & $\begin{array}{c}\text { Spiral sector } \\
\text { Curpose } \\
\text { therapy }\end{array}$ & Spiral sector \\
Particle & C $^{+6}$ & $\mathrm{C}^{+6}$ & ADSR \\
Energy & $20-400 \mathrm{MeV} / \mathrm{u}$ & $40-400 \mathrm{MeV} / \mathrm{u}$ & $200-1000 \mathrm{MeV} / \mathrm{u}$ \\
$\begin{array}{c}\text { Packing } \\
\text { factor }\end{array}$ & 0.535 & 0.35 & 0.33 \\
$\begin{array}{c}\text { Field index } \\
\text { Number of } \\
\text { cell }\end{array}$ & 4.2 & 3.6 & 9.0 \\
$\begin{array}{c}\text { Average } \\
\text { orbit radius } \\
\text { Spiral angle }\end{array}$ & $3.75-5.09 \mathrm{~m}$ & $2.6-3.45 \mathrm{~m}$ & $9.26-10.2 \mathrm{~m}$ \\
\hline \hline
\end{tabular}




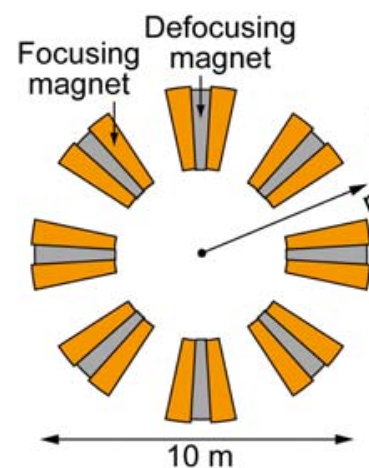

(a) R-C

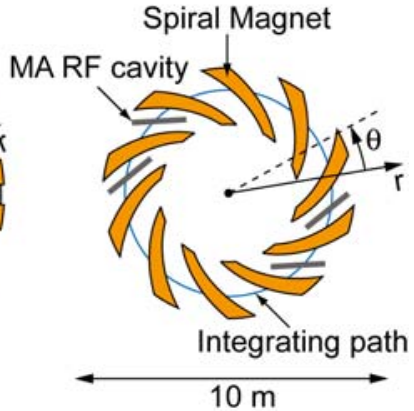

(b) S-C
Fig. 1. Footprints of magnets of accelerators for carbon cancer therapy: (a) radial sector FFAG accelerator R-C and (b) spiral sector FFAG accelerator S-C.

\section{DESIGNS OF MAGNETS}

The magnet designs for the accelerator R-C is shown in [12]. The designs of the magnet for the accelerator S-C and that for the accelerator $\mathrm{S}-\mathrm{A}$ are reported in this paper.

\section{A. Coil-Dominated Magnet for Spiral Sector FFAG Accelerator for Carbon Cancer Therapy}

Coil-dominated superconducting magnets are attractive to generate high magnetic fields [24]. As the first step to clarify the feasibility of coil-dominated superconducting magnets for spiral sector FFAG accelerators, we designed the coil of the magnet for the accelerator S-C, while the constraint on mechanical deformation of coated conductors was neglected. The procedure to design the coil is as follows [12].

1) The radial magnetic field profile of an FFAG accelerator can be expressed with the multi-pole expansion as follows.

$$
\begin{aligned}
& B(r)=B_{0}\left(r / R_{0}\right)^{k}=B_{0}\left\{\left(R_{0}+x\right) / R_{0}\right\}^{k} \\
& =B_{0} \sum_{n=1}^{\infty} r_{0}^{n-1} \frac{k !}{R_{0}^{n-1}(n-1) !\{k-(n-1)\} !}\left(\frac{x}{r_{0}}\right)^{n-1},
\end{aligned}
$$

where $R_{0}$ is the major radius of the accelerator, $r_{0}$ is the reference radius, and $x$ is the radial displacement from the magnet center. The magnetic field given by (1) can be generated by the cylindrical sheet current of radius $R_{\mathrm{c}}$ surrounding the beam as [24]

$$
i(\phi)=B_{0} \sum_{n=1}^{\infty} \frac{2 R_{\mathrm{c}}^{n}}{\mu_{0}} \frac{k !}{R_{0}^{n-1}(n-1) !\{k-(n-1)\} !} \cos (n \phi) .
$$

This can be transformed to an elliptic sheet current. The crosssectional positions of conductors on the elliptic mandrel are determined to simulate the elliptic sheet current.

2) The ellipse with conductor positions is rotated around the major axis of the accelerator to form a part of a toroid: conductors are expanded on the toroid. At the coil end, each conductor forms an arc with spiral angle: an inner conductor close to the accelerator center and the outer counterpart are connected with each other.
TABLE II

OUTLINE OF DESIGNED COIL OF MAGNET FOR ACCELERATOR S-C

\begin{tabular}{cc}
\hline k value & 3.6 \\
Major axis / minor axis of mandrel & $1.76 \mathrm{~m} / 1.10 \mathrm{~m}$ \\
$\begin{array}{c}\text { Distance between magnet center and } \\
\text { accelerator center, } R_{0}\end{array}$ & $3.02 \mathrm{~m}$ \\
Peak magnetic field at $r=R_{0} / 3.46 \mathrm{~m}$ & $1.86 \mathrm{~T} / 4.36 \mathrm{~T}$ \\
Integrated fields at $r=R_{0}$ for a magnet & $2.2 \mathrm{~T} \cdot \mathrm{m}$ \\
Current per conductor & $498 \mathrm{~A}$ \\
Number of turns & 18988 \\
Number of layers & 55 \\
Length of conductors per magnet & $94 \mathrm{~km}$ \\
\hline \hline
\end{tabular}

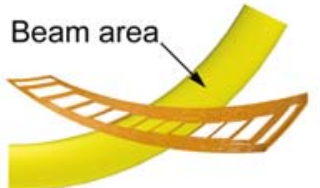

(a) Top view

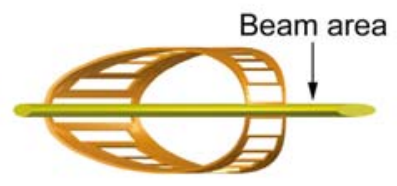

(b) Side view

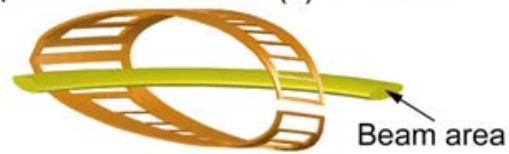

(c) Bird's-eye view

Fig. 2. Coil shape of coil-dominated magnet for accelerator S-C: (a) top view, (b) side view, and (c) bird's eye view.

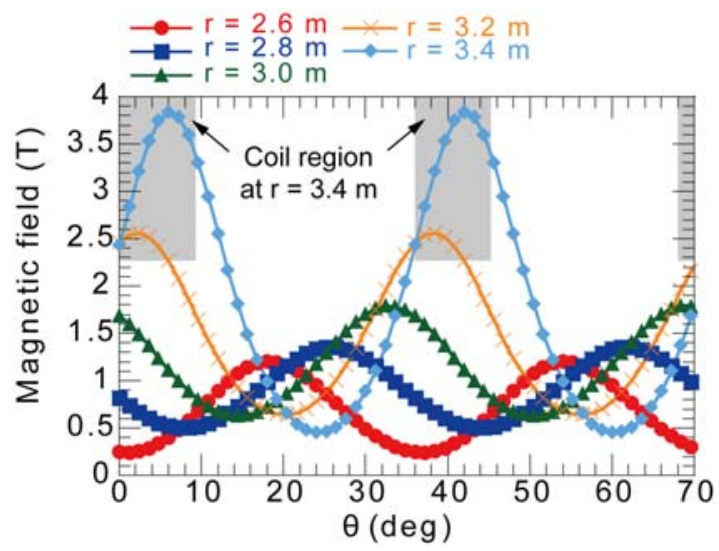

Fig. 3. Azimuthal magnetic field profiles of designed coil shown in Fig. 2.

3) When an accelerator consists of $N$ coils, the magnetic field is integrated over $(360 / N)$ degrees along the integrating path shown in Fig. 1(b) to obtain the integrated magnetic field $B_{\mathrm{L}}(r)$. Although the track of a particle is not a complete circle, the integration is made on the circle for simplification. This calculated $B_{\mathrm{L}, \mathrm{Cal}}(r)$ is compared with the $B_{\mathrm{L}, \mathrm{Spec}}(r)$ obtained from (1) to adjust the positions of conductor on a coil crosssection.

4) 1) through 3) are iterated until the local $k+1$,

local $k+1=\frac{\mathrm{d} B_{\mathrm{L}, \text { Cal }}(r)}{\mathrm{d} r} \frac{r}{B_{\mathrm{L}, \mathrm{Cal}}(r)}$,

converges to real $k+1$ determined as the specification. 


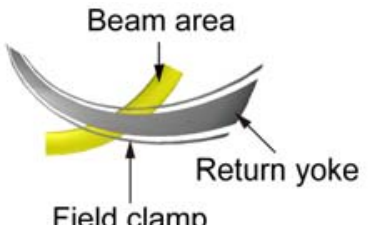

(a) Top view

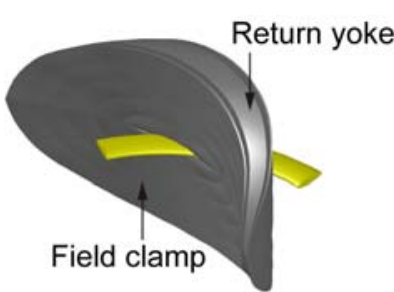

(c) Bird's-eye view

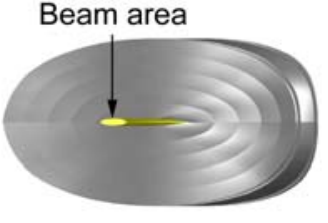

(b) Side view

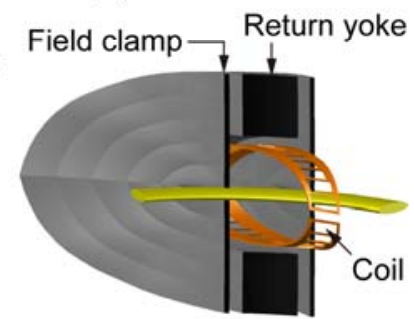

(d) Cross-sectional view

Fig. 4. Return yoke and field clamps together with coil.

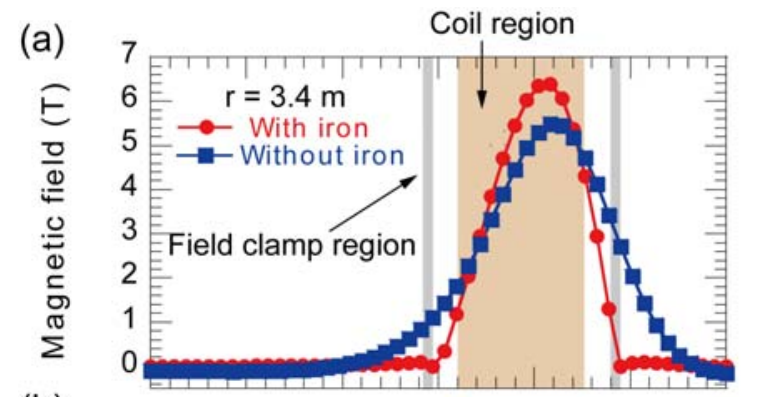

(b) 3

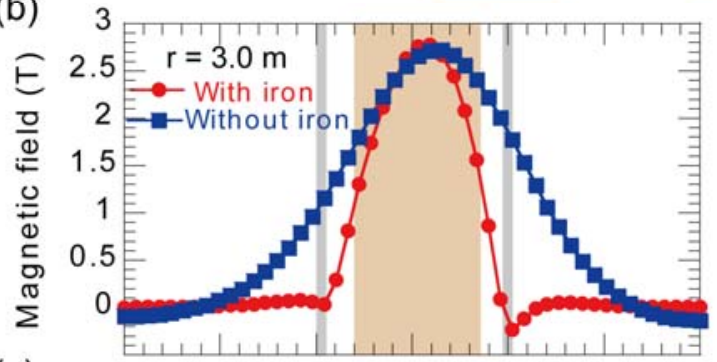

(c) 2.5

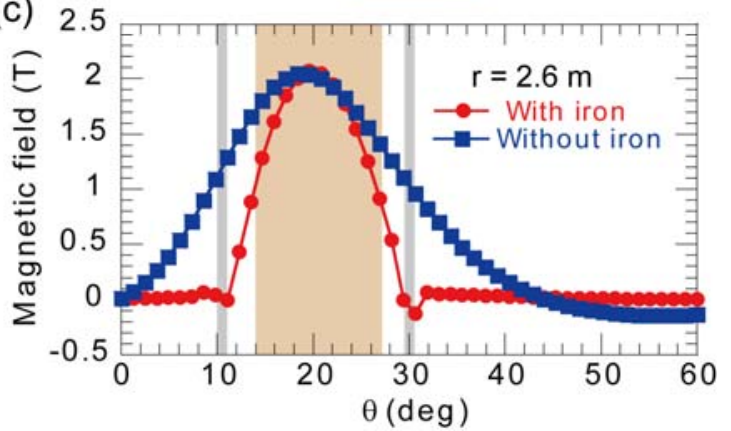

Fig. 5. Effect of return yoke and field clamps to reduce leakage magnetic field.

The outline and the shape of the designed coil are shown in Table II and Fig. 2. The azimuthal profiles of magnetic field are shown in Fig. 3.

So as to reduce the leakage magnetic flux from the coil ends shown in Fig. 3, an iron return yoke and field clamps were attached to the coil as shown in Fig. 4, and the magnetic field analyses were carried out. The relative permeability of the iron was set at 5000, neglecting its magnetic saturation. In Fig. 5,

the azimuthal profiles of the magnetic field with and without the return yoke and the field clamps are compared with each other. The leakage magnetic flux from the coil ends can be reduced effectively by the return yoke and the field clamps.

\section{B. Iron-Dominated Magnet for Spiral Sector FFAG Accelerator for ADSR}

In iron-dominated magnets, though the magnetic field strength is limited by the saturation of iron, electricity consumptions can be reduced by using HTS [25]. This is very attractive for ADSR, because the efficiency of its accelerator is critical for its realization. Fig. 6 and Table III show the irondominated magnet designed for the accelerator S-A. The iron is placed at room temperature, and only the superconductor coil is placed in a cryostat. The coil is installed in the cryostat placed in the slot of the iron as shown in Fig. 6(c). The operating current $\left(I_{\mathrm{op}}\right)$ of the coated conductor is 170 A at
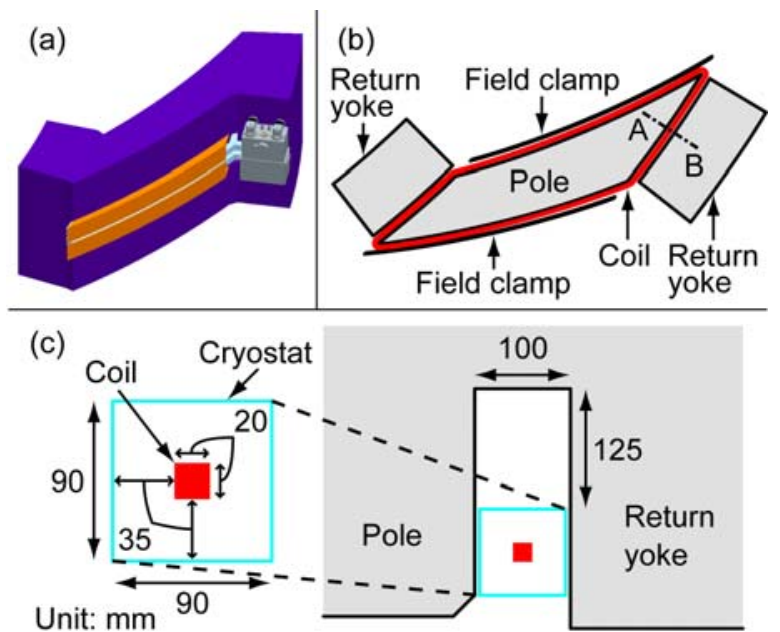

Fig. 6. Iron-dominated magnet for accelerator S-A: (a) entire magnet, (b) horizontal cross-section of magnet, and (c) cross-section of coil installed in a cryostat placed in a slot of iron yoke.

TABLE III

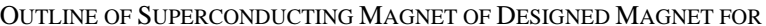
ACCELERATOR S-A

\begin{tabular}{cc}
\hline & \multicolumn{2}{c}{ ACCELERATOR S-A } \\
\hline \hline Ampere-turn & $20 \mathrm{~mm} \times 20 \mathrm{~mm}$ \\
Size of coil cross-section & $5 \mathrm{~mm} \times 0.2 \mathrm{~mm}$ \\
Size of conductor & $170 \mathrm{~A}$ \\
Current per conductor & $72 \%$ at $50 \mathrm{~K}$ and $39 \%$ at $20 \mathrm{~K}$ \\
Load rates of current & $170 \mathrm{~A} / \mathrm{mm}^{2}$ in conductor cross-section \\
Current density & $56 \mathrm{~A} / \mathrm{mm}^{2}$ in coil cross-section \\
Number of turns & $132 \times 2$ \\
Length of conductors & $1.1 \mathrm{~km} \times 2$ \\
Peak magnetic field & $0.97 \mathrm{~T}$ \\
at magnet center & $1.68 \mathrm{~T}$ \\
Peak magnetic field & \\
at $r=10.2 \mathrm{~m}$ & $0.625 \mathrm{~T}$ \\
Maximum magnetic field & \\
at conductor & \\
\hline \hline
\end{tabular}


$0.625 \mathrm{~T}$. Based on the critical current $\left(I_{\mathrm{c}}\right)$ - magnetic field $(B)$ and temperature $(T)$ dependence measured for a commercial class coated conductor [9], the load rates $\left(I_{\mathrm{op}} / I_{\mathrm{c}}\right)$ can be calculated for various temperature. When operated at $50 \mathrm{~K}$, the load rate is $72 \%$, and the coil can be cooled by using a GMcryocooler. Here, we calculated the efficiency of the accelerator S-A. The input power of a standard GMcryocooler is $6.5 \mathrm{~kW}$, and the number of GM-cryocooler is 32 . Therefore, the total input power required for GM-cryocoolers in the entire accelerator is $0.21 \mathrm{MW}$. Eleven RF cavities are installed in the accelerator S-A. When assuming that the input power of an RF cavity is $350 \mathrm{~kW}$, the total input power to RF cavities is 3.85 MW. Therefore, the total input power to the accelerator is about $4 \mathrm{MW}$. Meanwhile, the output power of the accelerator can be calculated as the product of its beam energy gain and the beam current. Here, the beam current of the accelerator is $2 \mathrm{~mA}$. Then the output power becomes 1.6 MW. Finally, the efficiency of the accelerator becomes around $40 \%$, which is high enough for the realization of ADSR.

\section{Winding TECHNOLOGIES}

Technologies to wind coils with three-dimensional shapes are required for coil-dominated magnets. Technologies to wind coils with negative bend are required for the magnets of spiral sector FFAG accelerators. Coils must be impregnated with epoxy resin to improve thermal conductivity for conduction cooling by using cryocooler [26]. R\&D of these technologies are carried out in our project [10], [13]. Target figures such as minimum bending radius of coated conductor, curvature to form three-dimensional coils, and the minimum radius of negative bend were set based on the specifications of the designed coils given in [12] and III.B. The schematics of fabricated reduced-size test coils are shown in Fig. 7: (a) shallow saddle-shape coil and (b) coil with negative bend. The number of turns of each coil is 100, and they were impregnated with epoxy resin. Each coil was cooled in liquid nitrogen, and their voltage - current characteristics were measured. In the shallow saddle-shape coil, the critical current of the innermost layer which was exposed to the largest magnetic field was $53 \mathrm{~A}$, which approximately agrees with the value calculated from the $I_{\mathrm{c}}-B$ characteristic of a short sample conductor. The measured $n$ value of the coil was above 20. A similar good voltage - current characteristic was observed in the coil with negative bend, too.

\section{Magnetization of CoAted Conductor}

One of the concerns of coated conductors for applications to accelerator magnets is their possible large magnetization caused by their wide tape shape [7], [12], [27]-[30]. To clarify how the magnetization deteriorates the field quality, we made a small dipole magnet shown in Fig. 8 and measured its multipole coefficients of magnetic field by rotating pick-up coils [14]. The magnet consists of a pair of stacked two racetrack coils wound with GdBCO coated conductors. All coils were impregnated with epoxy resin. The GdBCO coated conductors, manufactured by Fujikura Ltd., are $5 \mathrm{~mm}$ wide and $0.2 \mathrm{~mm}$ (a)

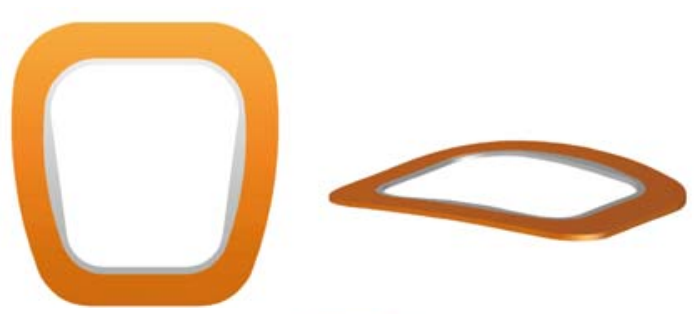

(b)

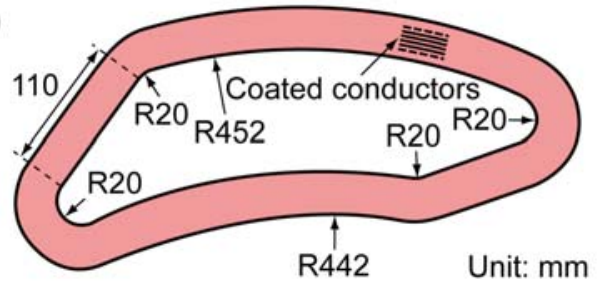

Fig. 7. Schematics of reduced-size test coils wound with coated conductors: (a) shallow saddle-shape coil and (b) coil with negative bend.

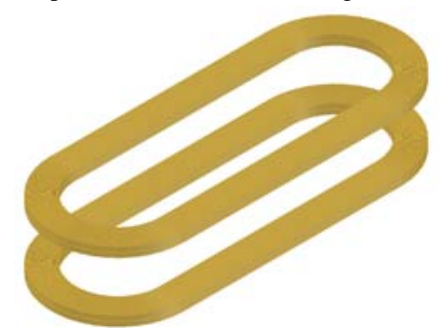

Fig. 8. Dipole magnet consisting of a pair of stacked two racetrack coils.

thick including copper stabilizer. Their critical current at $77 \mathrm{~K}$ is about $280 \mathrm{~A}$. The drifts of the dipole and sextupole coefficients normalized by the theoretical value of the dipole component were $4.8 \times 10^{-4}$ and $1.3 \times 10^{-4}$, respectively, in 8 hours. The magnetization of coated conductors apparently influences the generated magnetic field, but the drift of the multi-pole coefficients are rather small. Supposing the temporal stability of the magnetization, magnetic field corrections, by using correction coils, for example, might be a possible countermeasure to the issue of the magnetization.

\section{SUMMARY}

The coil-dominated magnet and the iron-dominated magnet for the spiral sector FFAG accelerator for carbon cancer therapy and that for ADSR were designed. We clarified the requirements for the winding technologies through designing coils and carried out the R\&D of the winding technologies. Shallow saddle-shape coils and coils with negative bend were fabricated, and their degradation-free superconducting properties were confirmed experimentally. Measured little drifts of multi-pole coefficients caused by decaying magnetization suggest magnetic field corrections as a possible countermeasure to the issue of the magnetization.

\section{REFERENCES}

[1] R. Gupta, M. Anerella, J. Cozzolino, J. Escallier, G. Ganetis, A. Ghosh, M. Harrison, A. Marone, J. Muratore, J. Schmalzle, W. Sampson, and P. 
Wanderer, "Status of high temperature superconductor magnet R\&D at BNL,” IEEE Trans. Appl. Supercond., vol. 14, no. 2, pp. 1198-1201, Jun., 2004.

[2] J. Muratore, J. Escallier, G. Ganetis, A. K. Ghosh, R. C. Gupta, P. He, A Jain, P. Joshi, P. Wanderer, M. Fee, and M. Christian "Magnetic field measurements of an HTS retrofit synchrotron dipole," IEEE Trans. Appl. Supercond., vol. 21, no. 3, pp. 1653-1656, Jun., 2011.

[3] R. Gupta, M. Anerella, G. Ganetis, A. Ghosh, H. Kirk, R. Palmer, S. Plate, W. Sampson, Y. Shiroyanagi, P. Wanderer, B. Brandt, D. Cline, A. Garren, J. Kolonko, R. Scanlan, and R. Weggel, "High field HTS R\&D solenoid for muon collider,” IEEE Trans. Appl. Supercond., vol. 21, no. 3, pp. 1884-1887, Jun., 2011.

[4] S. Ninomiya, K. Hatanaka, Y. Sakemi, T. Kawaguchi, and N. Takahashi, "The study of high magnetic field and AC operation of high temperature superconducting magnet," in Proc. Asian Particle Accelerator Conference 2004, Gyeongju, pp. 507-509, Mar., 2004.

[5] K. Hatanaka, S. Ninomiya, Y. Sakemi, T. Wakasa, T. Kawaguchi, and N. Takahashi, "Development of a HTS magnet and application to a beam scanner,” Nucl. Instr. Meth. in Phys. Res. Section A, vol. 571, no. 3, pp. 583-587, Feb., 2007.

[6] K. Hatanaka, J. Nakagawa, M. Fukuda, T. Yorita, T. Saito, Y. Sakemi, T. Kawaguchi, and K. Noda, "A HTS scanning magnet and AC operation," Nucl. Instr. Meth. in Phys. Res. Section A, vol. 616, no. 1, pp. 16-20, Apr., 2010.

[7] N. Amemiya, K. Takahashi, N. Okada, T. Nakamura, T. Ogitsu, T. Kurusu, M. Ono, M. Kodaira, and K. Noda, "Multi-pole components of magnetic field in dipole magnets wound with high $T_{\mathrm{c}}$ superconductor tape and feasibility of their accelerator applications," IEEE Trans. Appl. Supercond., vol. 20, no. 3, pp. 364-367, Jun., 2010.

[8] N. Amemiya, K. Takahashi, N. Okada, T. Nakamura, Y. Mori, T. Ogitsu, T. Tosaka, T. Kurusu, T. Yoshiyuki, K. Noda, and M. Yoshimoto, "A new project for research and development of fundamental technologies for applications of high $T_{\mathrm{c}}$ superconductor tapes to accelerator magnets," presented at Applied Superconductivity Conference 2010 (Washington D.C., U.S.A., August 2010).

[9] K. Takahashi, N. Amemiya, T. Nakamura, T. Ogitsu, T. Kurusu, T. Yoshiyuki, K. Noda, and S. Awaji, "Magnetic field design of dipole magnet wound with coated conductor considering its current transport characteristics," IEEE Trans. Appl. Supercond., vol. 21, no. 3, pp. 18331837, Jun., 2011.

[10] K. Koyanagi, T. Tosaka, K. Tasaki, T. Kurusu, T. Yoshiyuki, N. Amemiya, and T. Ogitsu, "Fabrication of YBCO small test coils for accelerator magnet development," IEEE Trans. Appl. Supercond., vol. 22, no. 3, p. 4101904, Jun., 2012.

[11] K. Takahashi, N. Amemiya, T. Nakamura, Y. Mori, T. Ogitsu, M. Yoshimoto, I. Watanabe, and T. Yoshiyuki, "Magnetic field design of coil-dominated magnets wound with coated conductor,” IEEE Trans. Appl. Supercond., vol. 22, no. 3, p. 4901705, Jun., 2012.

[12] N. Amemiya, K. Takahashi, H. Otake, T. Nakamura, Y. Mori, T.Ogitsu, K. Koyanagi, A. Osanai, T. Yoshiyuki, K. Noda, and M. Yoshimoto, "Research and development of fundamental technologies for accelerator magnets using high $T_{c}$ superconductors” Physica C, Jul., 2012. accepted for publication. http://dx.doi.org/10.1016/j.physc.2012.05.017

[13] K. Koyanagi, S. Takayama, T. Tosaka, K. Tasaki, T. Kurusu, T. Yoshiyuki, N. Amemiya, and T. Ogitsu, "Development of saddle-shaped coils using coated conductors for accelerator magnet," presented at Applied Superconductivity Conference 2012 (Portland, Oregon, U.S.A., October 2012).

[14] N. Amemiya, H. Otake, T. Nakamura, T. Ogitsu, K. Koyanagi, and T. Kurusu, "Influence of magnetization of coated conductors on magnetic field harmonics in accelerator magnet," presented at Applied Superconductivity Conference 2012 (Portland, Oregon, U.S.A., October 2012).
[15] T. Aoki, H. Ueda, A. Ishiyama, N. Miyahara, N. Kashima, and S. Nagaya, "Effect of Neutron Irradiation on High-Temperature Superconductors,” IEEE Trans. Appl. Supercond., vol. 21, no. 3, pp. 3200-3202, Jun., 2011.

[16] A. Godeke, D. W. Cheng, D. R. Dietderich, C. R. Hannaford, S. O. Prestemon, G. Sabbi, X. R. Wang, Y. Hikichi, J. Nishioka, and T. Hasegawa, "Progress in wind-and-react Bi-2212 accelerator magnet technology,” IEEE Trans. Appl. Supercond., vol. 19, no. 3, pp. 22282231, Jun., 2009.

[17] A. Godeke, P. Acosta, D. Cheng, D. R. Dietderich, M. G. T. Mentink, S. O. Prestemon, G. L. Sabbi, M. Meinesz, S. Hong, Y. Huang, H. Miao, and J. Parrell, "Wind-and-react Bi-2212 coil development for accelerator magnets," Supercond. Sci. Technol., vol. 23, no. 3, p. 034022, Mar., 2010.

[18] X. Wang, S. Caspi, D. W. Cheng, D. R. Dietderich, H. Felice, P. Ferracin, A. Godeke, J. M. Joseph, J. Lizarazo, S. O. Prestemon, and G. Sabbi, "Measurements on subscale Y-Ba-Cu-O racetrack coils at $77 \mathrm{~K}$ and self-field," IEEE Trans. Appl. Supercond., vol. 20, no. 3, pp. 368372, Jun., 2010.

[19] G. Nielsen, N. Zangenberg, D. Hazelton, N. Hauge, B. R. Nielsen, S. P. Møller, A. Baurichter, "Dipole magnet from high Tc superconductor," Physics Procedia, vol. 36, pp. 824-829, 2012.

[20] N. Zangenberg, G. Nielsen, N. Hauge, B. R. Nielsen, A. Baurichter, C. G. Pedersen, L. Bräuner, B. Ulsøe, and S. P. Møller, "Conduction cooled high temperature superconducting dipole magnet for accelerator applications," IEEE Trans. Appl. Supercond., vol. 22, no. 3, p. 4004004, Jun., 2012.

[21] K. R. Symon, D. W. Kerst, L. W. Jones, L. J. Laslett, and K. M. Terwilliger, "Fixed-field alternating-gradient particle accelerators," Phys. Rev., vol. 103, no. 6, pp. 1837-1859, Jun., 1956.

[22] S. Machida, Y. Mori, and R. Ueno, "Beam optics design of an FFAG synchrotron,” Proceedings of European Particle Accelerator Conference, pp. 557-559, 2000.

[23] T. Obana, T. Ogitsu, T. Nakamoto, K. Sasaki, A. Yamamoto, T. Orikasa, M. Yoshimoto, and Y. Mori, "Magnetic field design of superconducting magnet for a FFAG accelerator,” IEEE Trans. Appl. Supercond., vol. 15, no. 2, pp. 1185-1188, June, 2005.

[24] S. Russenschuck, Field computation for accelerator magnets. Weinheim: WILEY-VCH, 2010, pp. 293-326.

[25] S. Russenschuck, Field computation for accelerator magnets. Weinheim: WILEY-VCH, 2010, pp. 269-291.

[26] H. Miyazaki, S. Iwai, T. Tosaka, K. Tasaki, S. Hanai, M. Urata, S. Ioka, and Y. Ishii, "Thermal stability of conduction-cooled YBCO pancake Coil,” IEEE Trans. Appl. Supercond., vol. 21 no. 3, pp. 2453-2457, Jun., 2011.

[27] N. Amemiya and K. Akachi, "Magnetic field generated by shielding current in high $\mathrm{T}_{\mathrm{c}}$ superconducting coils for NMR magnets," Supercond. Sci. Technol., vol. 21, no. 9, p. 095001, Sep., 2008.

[28] M. C. Ahn, T. Yagai, S. Hahn, R. Ando, J. Bascunan and Y. Iwasa, "Spatial and Temporal Variations of a Screening Current Induced Magnetic Field in a Double-Pancake HTS Insert of an LTS/HTS NMR Magnet,” IEEE Trans. Appl. Supercond., vol. 19, pp. 2269-2272, Jun., 2009.

[29] Y. Yanagisawa, Y. Kominato, H. Nakagome, R. Hu, T. Takematsu, T. Takao, D. Uglietti, T. Kiyoshi, M. Takahashi and H. Maeda, "Magnitude of the Screening Field for YBCO Coils,” IEEE Trans. Appl. Supercond., vol. 21, pp. 1640-1643, Jun., 2011.

[30] A. Otsuka, Y. Yanagisawa, T. Kiyoshi, H. Maeda, H. Nakagome and M. Takeda, "Evaluation of the Screening Current in a $1.3 \mathrm{GHz}$ NMR Magnet Using ReBCO,” IEEE Trans. Appl. Supercond., vol. 21, pp. 2076-2079, Jun., 2011. 